\title{
Communication dimension of a Facebook group: first-hand experience from an EAP class
}

\author{
Juraj Datko \\ Constantine the Philosopher University in Nitra, Slovakia; jdatko@ukf.sk
}

\begin{abstract}
The paper analyses student-teacher and student-student interactions in a Facebook group that was created as an alternative learning management system (LMS) for an English for Academic Purposes (EAP) course. Our case study is based on students' perceptions and opinions reconstructed from interviews and diaries and uses traceable objective data from the Facebook group as a complement. The research sample includes thirty-four undergraduates. Our results indicate that Facebook group is perceived as an effective communication channel due to various reasons such as immediacy of feedback or peer interactions outside the language class. Based on our findings, we formulate recommendations for practice.
\end{abstract}

Keywords: Facebook group, student-teacher/student-student communication, teaching/learning English as a foreign language, university student, case study

\section{Introduction}

Although Facebook is usually bound with personal life, leisure time, and informality, different authors researched the use of this tool in formal, academic settings. They studied its application in different higher education contexts and focused on various aspects such as motivation (Kabilan, Ahmad \& Abidin 2010, Simpson 2012, Türkmen 2012, Hsu 2013), student involvement (Pascopella \& Richardson 2009, Sun 2010, Yunus et al. 2012, Kao \& Craigie 2014), e-learning (Stewart 2009, Türkmen 2012), social learning (Kabilan, Ahmad \& Abidin 2010, Razak, Saeed \& Zulkifli 2013), autonomous learning (Laire, Casteleyn \& Mottart 2012, Túrkmen 2012, Yunus et al. 2012, Datko 2018a), or communication (Al-Shehri 2011, Simpson 2012, Small 2014).

Communication (spoken and textual) is one of the pillars of both social networks and foreign language education (FLE). In other words, it is a tool for verbal interaction and developing foreign language competence. To use a Facebook group as an out-of-the-class communication channel and a learning tool in an English as a foreign language (EFL) educational setting was a choice based on social constructivism in which conversation and collaboration are seen as key concepts of learning (McLoughlin \& Lee 2010). Since Z-Gen learners are highly connected and collective (Selwyn 2010), these notions become prominent in their approaches to learning and thus provide a solid foundation for the application of the discussed communication tool into the EFL learning process.

The purpose of this study is to map the communication dimension of a Facebook group in an EFL learning environment from the perspective of content-interchange among students and between students and their teacher. However, the focus is on how students used Facebook to connect with one another and the teacher, rather than how they used it to develop their communicative competences. In other words, the language learning potential of this communication channel is not discussed here (see Datko, 2018b for further reading on this topic).

\section{Literature review}

Speaking within the confines of higher education in general, social networking sites (SNSs) enhance student-student (S-S) interaction outside the classroom. In a study conducted by Brady, Holcomb and Smith (2010) at North Carolina State University, a survey was performed with students $(N=50)$ in order to explore their perceptions of integrating Ning (a SNS) in the education process. They concluded that it facilitated communication beyond the boundaries of the classroom (82\%) and provided more communication opportunities than contact classes (70\%). Ophus and Abbitt (2009) found that peercommunication is seen as one of the major benefits of a Facebook group for $95.5 \%(\mathrm{~N}=100)$ university 
students who experienced a multi-modal biology instruction that blended this "alternative" learning management system with traditional classroom. Similar findings were also proposed by Irwin, Ball and Desbrow (2012) and Jong et al. (2014), as majority of their participants (78\% - N=135 and 59\% - N=261 respectively) highlighted S-S interaction as one of the main advantages of using this platform in formal education. The above shows that S-S interaction (also outside the classroom) is perceived by students as an important asset of a blended-learning model based on SNSs.

FLE research highlights the potential of both peer interaction and student-teacher (S-T) interaction via social networks. Al-Shehri (2011) and Yunus et al. (2012) agreed that social networks' independence from time and space enhances interaction between students and pedagogues outside the context of the English classroom. They can discuss assignments and study problems, share ideas, or give/get feedback. Razak, Saeed \& Zulkifli (2013) suggest that this can lead to improvements in students' English. Based on the perceptions of students $(\mathrm{N}=24)$ who participated in their study, they concluded that communication with classmates and the teacher via the Facebook group was one of the key players in enhancing students' writing skills (ibid.).

However, if a (language) teacher decides to employ Facebook as a communication tool in an educational setting, a few aspects must be considered a priori. First, we have to accept the fact that this type of electronically-mediated communication has an uncontrollable and unpredictable nature; therefore, what is considered red-hot today may be irrelevant or deleted tomorrow (Laire, Casteleyn \& Mottart 2012). Second, as Facebook denotes non-formality, we must expect that students communicate about academic matters rarely (Roblyer et al. 2010). Third, due to the relaxed atmosphere, tolerance for mistakes can develop, resulting in deviant uses of the language such as simplified syntax, informal contractions and abbreviations, or emojis (Averianova 2012). Furthermore, Facebook seems to lower students' cautiousness of grammar and orthography and encourages them to use incorrect language forms (Andwaruddin, 2012). Fourth, the level of teachers' self-disclosure in their Facebook profiles correlates with the level of credibility in the eyes of the students (Mazer, Murphy \& Simonds 2007).

\section{Research strategy}

Research aims

It was stated in the theory that students benefit from out-of-class interactions via SNSs in various aspects (e.g. increase in communication opportunities when compared to traditional classes or positive impact on English writing skills), but a deeper context is missing. We therefore believe that studying how Facebook S-S and S-T interactions are perceived by students of English and what is the scope of these interactions will shed more light on this topic.

The primary aim of the paper is to identify how university students perceive S-T and S-S communication via the Facebook platform. The secondary aim is to quantify and categorize S-T and S-S interactions through the Facebook group and messages. In relation to the set aims, we strive to answer the following question: What do EFL students' perceptions and opinions and objective data from the Facebook group reveal about S-T and S-S communication via Facebook?

Our research project is designed as a case study, since this approach is widely used for researching computer-assisted language learning contexts (Beatty 2010). It uses three types of data collection tools, namely diaries, semi-structured interviews, and screenshots.

\section{Participants}

Undergraduates from a mid-sized university $(\mathrm{N}=34)$ participated in this study. The research participants were teacher trainees $\left(\mathrm{N}_{1}=22\right)$ and "Occupational Safety and Health" students $\left(\mathrm{N}_{2}=12\right)$. They were labelled either with "a" (cohort 1 - summer 2016/2017) or with "b" (cohort 2 - winter 2017/2018). The students enrolled in the EAP optional course taught by the author. They all agreed to participate in 
the Facebook group and gave permission for their information to be used for research purposes. Ethical approval was granted by the university.

Seventeen interviewees were selected randomly from the whole sample. The interviews lasted between $17^{\prime} 46^{\prime \prime}$ and $50^{\prime} 30^{\prime \prime}$ and were transcribed by the researcher. All research participants $(\mathrm{N}=34)$ kept diaries and submitted them physically on a weekly basis, producing 606 entries in total. Both the diaries and the Facebook screenshots cover an eight-week period of the course.

\section{Data collection}

Semi-structured interviews represent primary data. This research instrument was used for the reconstruction of students' perceptions and opinions related to S-T and S-S Facebook communication. We conducted pre-interviews (after students' first contact with the Facebook group) and post-interviews (after the study experience with the Facebook group) to increase reliability and validity of the data. We asked the students how they perceive this communication channel, what do they value about it, or what do they use it for.

Semi-structured student diaries serve as secondary, supporting data and are subordinated to the interviews. Their role was to further validate the pre-/post-interviews and illuminate hidden, unnoticed contexts of students' communication activities. The students were asked to record and describe in detail their interactions (both public - comments or statues and private - direct messages) with other group members.

The third type of research data was extracted from the "English for Academic Purposes 1" Facebook group in the form of screenshots. We took screenshots of all the visible S-T and S-S communications. The data gathered from the Facebook group served as the objective complement to the subjective interview and diary data.

\section{Data analysis}

In the first stage of the analytic process, we opted for inductive coding, because the study is exploratory in nature. We identified items relevant to our research in the raw interview transcripts and categorized them with preliminary codes (e.g. S-T communication via Facebook is faster, S-T communication via Facebook is comfortable, Facebook as a tool for S-S communication about study material, etc.). These initial codes were further refined as we proceeded with the process, resulting in the final coding system (summarized in Table 1).

In the second stage, we switched to deductive coding, since student diaries complemented the interviews. In other words, the diaries were processed by seeking out entries related to the interview codebook. However, two of the identified codes remained interview-exclusive.

The third stage focused on content analysis of the objective Facebook data. The "history" of the Facebook group activity was stored in screenshot form. It provided supporting evidence for some of the code labels from the interviews and diaries.

\section{Findings}

\section{S-T Communication}

Twenty-seven participants (13 from cohort 1 and 14 from cohort 2) provided data related to this category. It is important to mention that the acronym S-T encompasses both the interactions initiated by the teacher and the interactions with student initiation.

Among other study activities in the Facebook group, eight students ( 5 from cohort 1 and 3 from cohort 2) recorded thirteen times in their diaries that they interacted with the teacher in some way. These S-T interactions included:

(1) receiving feedback from the teacher via comments or messages (cohort 1: 4, cohort 2: 2);

(2) sending completed assignments in messages (cohort 1: 3, cohort 2: 2); 
(3) communication about unfamiliar concepts in the study material via comments (cohort 1: 1).

The analysis of the available Facebook group data enabled a deeper insight into the discussed topic. Twenty-four students (11 from cohort 1 and 13 from cohort 2) exchanged 237 messages with the teacher. Similar to the diaries mentioned above, students sent files with completed extra tasks (11 from cohort 1 and 11 from cohort 2), received feedback (11 from cohort 1 and 11 from cohort 2), and asked for course information (4 from cohort 1 and 1 from cohort 2). There was not a single example of S-T chat regarding study problems. Research participants communicated in English or Slovak, while both formal and informal language forms (including deviant uses) were noticed (see Figure 1).

Figure 1: Examples of S-T communication via private messages.

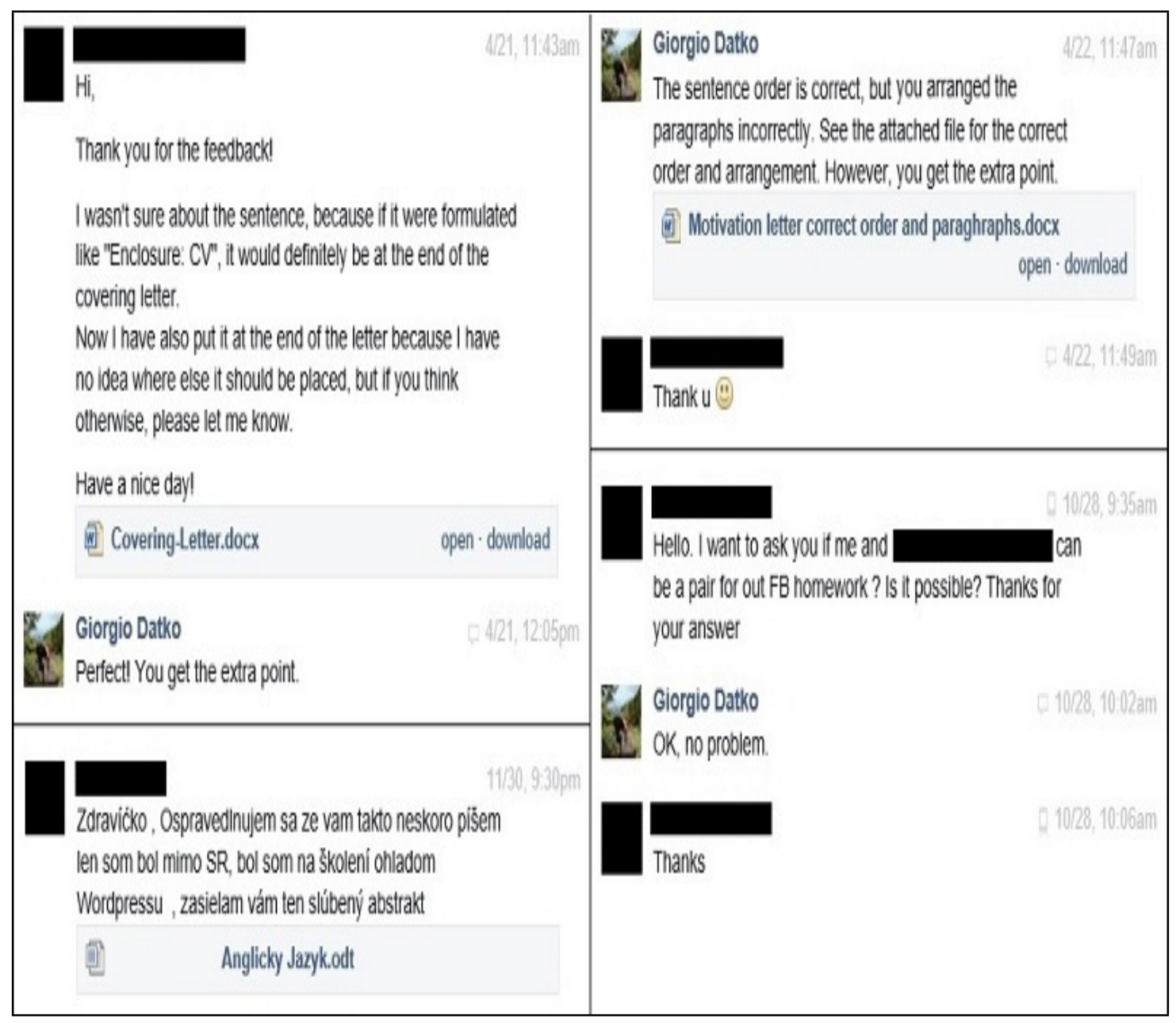

The teacher also communicated with the group members via comments and statuses (Figure 2). The comments enabled the researcher to give feedback for individuals (though it was also visible to the audience). From the fifty-seven teacher's comments in the study group, thirty-eight were related to feedback and in nineteen cases the teacher gave assignment instructions.

As for the status updates, they were used for explaining the given tasks and giving feedback or course information to the class as a whole. The teacher wrote thirty-eight statuses in total from which eighteen introduced tasks, seventeen contained course information, and three expressed feedback for the whole group. 
Figure 2: Examples of S-T communication via comments and statuses.

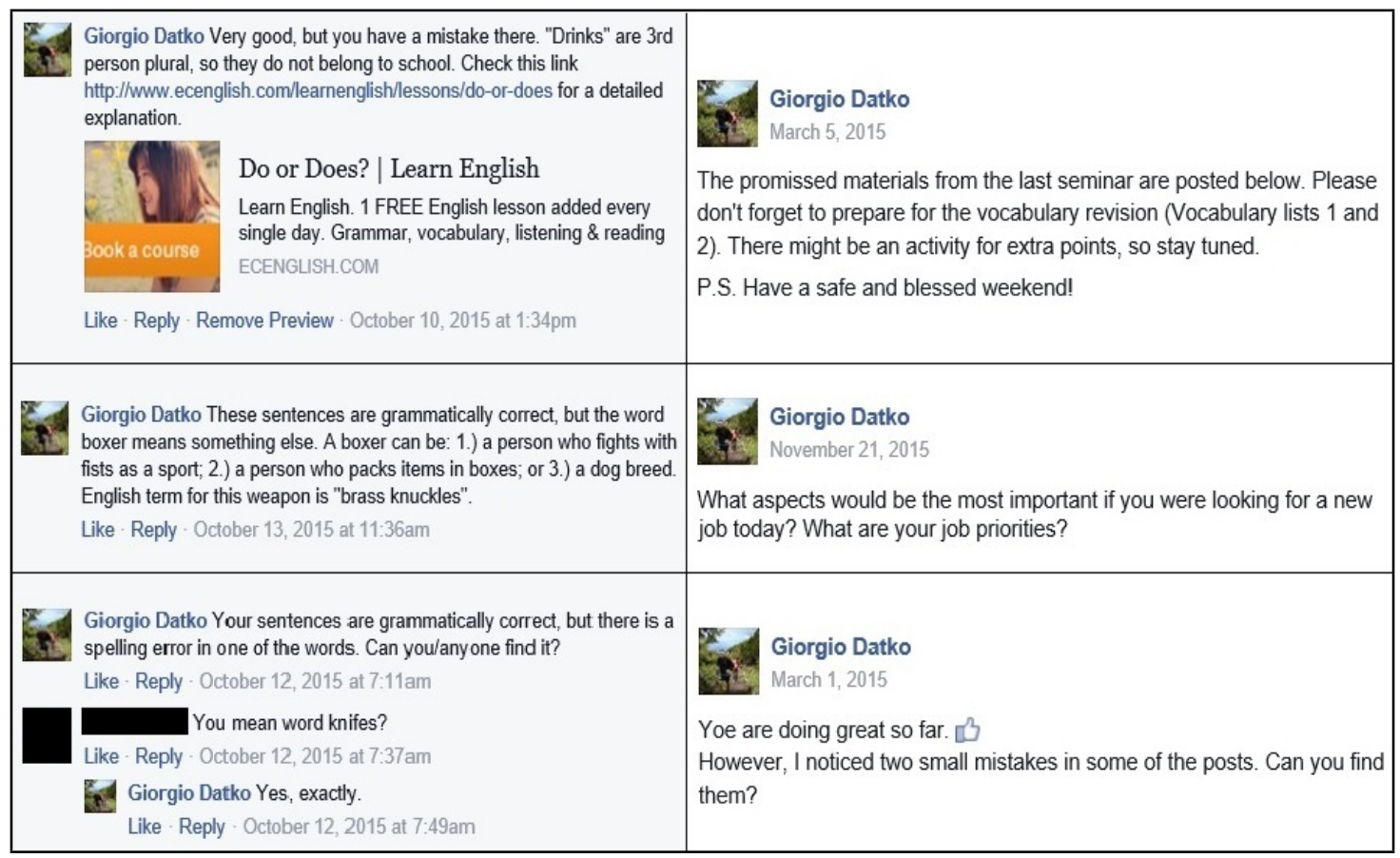

Let us now focus on the coding system for this category. Twenty-three students noticed improvements in S-T interaction. They referred to three different improvements fifty-three times (30x in the interviews and $23 x$ in the diaries).

\section{Facebook speeds up S-T communication}

A group of twenty students (9 from cohort 1 and 11 from cohort 2) felt that Facebook speeds up S-T communication. Four different aspects of this improvement occurred forty-four times in the subjective data (twenty-four times in the interviews and twenty times in the diaries).

Facebook meant an improvement in S-T communication for student $8 \mathrm{~b}$, because "it was faster than email". In the diary, he termed this way of communication as "immediate, simple, and non-problematic". Student $20 \mathrm{~b}$ maintained a positive attitude towards Facebook communication with the teacher due to the promptness of response. Student $16 \mathrm{~b}$ reported that "not every teacher has the university mail account connected to his smartphone. E-mail communication is thus not as fast as Facebook communication". Improved interaction with the teacher was also marked as one of the benefits in his diary. Student 10a messaged the teacher and received his answer "almost immediately, definitely faster than via e-mail", and thus it was "better for communication with teachers", as she explained in the postinterview. Six students ( 3 from cohort 1 and 3 from cohort 2) mentioned related data in their diaries. They valued Facebook for fast communication with the teacher and prompt teacher's feedback via comments or messages.

Students $13 a, 17 a$, and $6 b$ complained about some teachers' e-mail response routines and were therefore more inclined to Facebook. In the case of student 13a, it was uncovered in the post-interview that some teachers do not reply to e-mails, but "it was fast here". She concluded: "Communication via Facebook suits me best". According to the first interview with student 17a, "teachers not always reply to [her] e-mails", but on Facebook, the teacher can read [her] message immediately, "so it is faster". Student $6 \mathrm{~b}$ noted in her diary: "Communication with you as the teacher was faster this way. It happened many times that a teacher did not respond to my e-mail". 
Four students (cohort 1 ) added ease of access to the fast nature of Facebook. Students $2 a$ and $7 a$ claimed in the interviews that this form of communication suits them best, since they do not have to log in to their student mail accounts to contact the teacher. "I give Facebook ten points and e-mail gets maybe two" (student 7a, pre-interview). Another interviewee (student 4a) admitted to "access the student mail sporadically". She was more often on Facebook and could "see [teacher's] messages immediately". Student 18a valued Facebook in S-T communication, because she does not "have time to read every e-mail from teachers". She added in the post-instruction interview that "it can take some time until the teacher reads an e-mail".

Two students (cohort 2) viewed Facebook communication as fast due to lesser formality. In the pre-interview, student $14 \mathrm{~b}$ mentioned that "it is simpler and more comfortable than writing an email", since "e-mail communication is more formal". She added in the second interview that "promptness is a big advantage". Student $9 \mathrm{~b}$ agreed with her opinion by saying that "communication via the Facebook group is immediate", and as "it is also less formal, it does not take so long to formulate a message". Furthermore, the teacher's authority "remained intact even though we did not communicate via e-mail" (post-interview).

Four students (from cohort 2) liked the prompt feedback from the teacher. In his diary, student 9b praised "the opportunity to correct mistakes in [his] posts prior to the seminar thanks to prompt feedback from the teacher". Similarly, student $5 b$ reported in the initial interview that she "did not have to wait the whole week for [teacher's] feedback". She would even expect from the teacher to "respond in a shorter time than via e-mail". The fact that "the feedback was immediate" was a benefit also for interviewee $18 \mathrm{~b}$. Additionally, student $7 \mathrm{~b}$ appreciated in the diary that the teacher responded to students' activities in a short time.

\section{Facebook makes S-T communication more personal}

Four research participants (1 from cohort 1 and 3 from cohort 2) preferred this communication channel to e-mail, because it enabled a more direct and personal contact with the teacher. This code was identified five times (three times in the interviews and twice in the diaries).

Student $17 \mathrm{~b}$ considered the "more personal approach from the teacher to be a benefit of the Facebook group" (diary entry). In the initial interview, student 2a favored Facebook communication because "it is more personal". Similarly, student 20b "liked that it was more personal than e-mails" (post-interview). Student 8b replied in the first interview: "I think that contact via the group is more personal. When I think of e-mails, there is this superiority".

Facebook fosters S-T communication outside the classroom

Two students (from cohort 1) agreed on this. This code was recognized four times, namely three times in the interviews and once in the dairy.

In her diary, student 16a viewed the availability of teacher's comments beyond the class as a likeable outcome of the group. Student 14a speculated in the interviews that if a teacher cannot come to the seminar or forgets to send study materials, he can still add a posting in the Facebook group. "It spreads among students almost immediately. However, if he sends an e-mail, only few people read it [...] and then misunderstandings occur".

\section{Facebook does not improve S-T communication}

Opposing to the rest, one participant (from cohort 1) did not notice any improvement in S-T communication. In particular, student 12a stated in the post-interview: "Communication via e-mail is the same as communication via Facebook. Both of them require the Internet. I do not see there any improvement". 


\section{S-S Communication}

A group of twenty-five students ( 8 from cohort 1 and 17 from cohort 2) referred to communication among students. Twenty-three participants (seven from cohort 1 and 16 from cohort 2) mentioned $\mathrm{S}-\mathrm{S}$ communication seventy times in the diaries. These students used private chat to discuss coursework, while they recorded the following scopes of their interactions:

(1) homework:

- discussing pair homework (cohort 1:4, cohort 2:8);

- seeking further explanation of teacher's instructions (cohort 2: 9);

- discussing how others completed a task (cohort 2: 6);

- giving/receiving feedback on completed assignments (cohort 1: 1, cohort 2: 4).

(2) course info:

- seeking information about missed contact classes (cohort 2: 3);

- seeking information about upcoming tests (cohort 1: 1, cohort 2: 1).

(3) study materials:

- discussing unfamiliar concepts (cohort 1: 3, cohort 2: 2).

As Facebook does not enable the user to monitor others' communication via messages, it is not possible to objectively validate students' diary entries related to S-S interaction via chat. However, since the number of recorded S-S interactions is significantly higher than the number of recorded S-T interactions, we can guess that the participants tended to communicate about educational matters with their peers rather than with the teacher. Furthermore, none of the students initiated a S-T chat about study difficulties, thus it seems that they seek assistance among other classmates.

In the Facebook data visible to the researcher, we identified nine examples of S-S communication. Student $9 \mathrm{~b}$ commented on a posting from another student. Student 16a mentioned a classmate in her comment, because she wanted to remind her about homework. Student $19 \mathrm{~b}$ explained a task to student $16 \mathrm{~b}$ (who did not attend a seminar) in a series of comments. Student 4a informed the rest of the group about cancelled interviews in a status. Student $5 b$ posted a photo of her poster in order to help other group members to prepare for a test. Three of these student interactions are depicted below (Figure 3).

Figure 3: Examples of S-S communication via comments and a status.

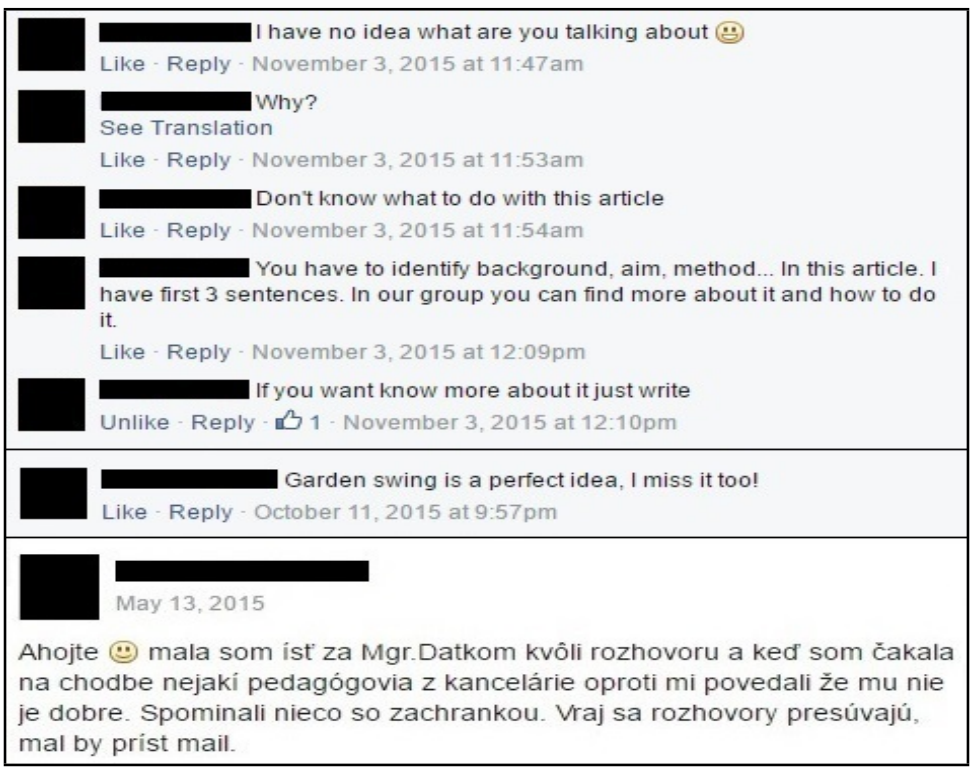


From the twenty-five participants discussed within this category, thirteen claimed that the Facebook group improved S-S communication. Evidence related to three different improvements appeared twenty-six times in the collected data. Particularly, we identified five examples in the interviews and twenty-one instances in the diaries.

\section{Facebook speeds up and eases S-S communication}

Nine students ( 3 from cohort 1 and 6 from cohort 2) agreed that the Facebook group speeds up and eases communication among students. For example, student $6 \mathrm{~b}$ noted in the diary that "Thanks to the group we can easily contact our classmates from the seminar. It is the fastest way of communication between students". In his diary, student 9b similarly labelled the group as "an easy and fast way of communication among students". Student $12 \mathrm{~b}$ reported in his diary that it is "a very good way of communication with other classmates" because he "can get information from others almost immediately". Student $18 \mathrm{~b}$ felt that communication with other students was easier, since they "could be easily found via the group". In the first interview, she expressed the same opinion as in the diary record: "I don't have to look for my classmates using the search option on Facebook, so communication is definitely easier". Furthermore, "[...] I messaged other classmates, and they answered immediately. It was definitely faster" (post-interview). Adding to this, student 4a wrote in her diary that in case she did not understand something, "the group made contacting unknown people easier".

\section{Facebook allows S-S communication about coursework}

Three participants ( 1 from cohort 1 and 2 from cohort 2 ) perceived positively that the Facebook group provides an opportunity to discuss classwork. Student 10a "once missed a seminar and wanted to get some information". According to one of her post-interview responses, she "looked for a classmate among the group members and contacted her in chat". Student $5 b$ liked that students "can ask other group members for help or highlight mistakes in others' comments". In his diary, student $11 b$ valued "students' hints about what should be corrected in [his] comments".

\section{Facebook fosters S-S communication outside the classroom}

Student $10 \mathrm{~b}$ valued that the Facebook group allowed him to stay in contact with his classmates beyond contact lessons. He was "very happy about the improved student communication outside the classroom", as he replied in the second interview.

Table 1: S-T and S-S communication via the EAP 1 Facebook group.

\begin{tabular}{|c|c|c|c|}
\hline Categories & Codes & Sub-codes & $\begin{array}{l}\text { Times occurred }+ \\
\text { source }\end{array}$ \\
\hline \multirow{6}{*}{ S-T communication } & \multirow{4}{*}{$\begin{array}{l}\text { I.) Facebook } \\
\text { speeds up S-T } \\
\text { communication }\end{array}$} & $\begin{array}{l}\text { a.) Facebook communication is } \\
\text { faster than e-mail communication }\end{array}$ & \multirow{4}{*}{ 44x (I: 24x; D: 20x) } \\
\hline & & $\begin{array}{l}\text { b.) Facebook communication is } \\
\text { faster than e-mail communication } \\
\text { due to ease of access }\end{array}$ & \\
\hline & & $\begin{array}{l}\text { c.) Facebook communication is } \\
\text { faster than e-mail communication } \\
\text { due to lesser formality }\end{array}$ & \\
\hline & & $\begin{array}{l}\text { d.) Facebook enables prompt } \\
\text { teacher's feedback }\end{array}$ & \\
\hline & \multicolumn{2}{|c|}{$\begin{array}{l}\text { II.) Facebook makes S-T communication more } \\
\text { personal }\end{array}$} & $5 x(I: 3 x ; D: 2 x)$ \\
\hline & \multicolumn{2}{|c|}{$\begin{array}{l}\text { III.) Facebook fosters S-T communication outside the } \\
\text { classroom }\end{array}$} & 4x (I: 3x; D: 1x) \\
\hline
\end{tabular}




\begin{tabular}{|c|c|c|}
\hline & IV.) Facebook does not improve S-T communication & $1 x(I: 1 x)$ \\
\hline \multirow{3}{*}{ S-S communication } & I.) Facebook speeds up and eases S-S communication & 21x (I: 2x; D: 19x) \\
\hline & $\begin{array}{l}\text { II.) Facebook allows S-S communication about } \\
\text { coursework }\end{array}$ & 4x (I: 2x; D: 2x) \\
\hline & $\begin{array}{l}\text { III.) Facebook fosters S-S communication outside the } \\
\text { classroom }\end{array}$ & $1 x(I: 1 x)$ \\
\hline
\end{tabular}

Legend: S-T communication - a wider category used to cover related data; I.) Facebook speeds up S-T communication - a more precise code used to cover similar data; a.) Facebook communication is faster than email communication - a sub-code used to further differentiate data within a code; 44x (I: 24x; D: 20x) - the code was recognized forty-four times in the data (24x in the interviews and $20 x$ in the diaries)

\section{Conclusion}

According to the data from the study group, twenty-four students exchanged 237 messages with the teacher. They interacted in Slovak or English and used both formal and informal language. It could be connected not only with the relaxed nature of the Facebook study group, but also with the lack of strict communication rules.

The analyzed S-T communication via chat was connected with sending completed tasks, receiving feedback from the teacher, and asking for course information. No S-T chat regarding study problems was recognized among the analyzed messages, in spite of the unprecedented availability of the teacher. Due to unavailability of data, we can only speculate why students hesitated to contact him when seeking help with study activities. It seems that they rather messaged their peers, which might be caused by the traditional respect to the teacher authority, high power distance dimension of the Slovak culture, or they simply did not want to admit having study problems.

Comments and statuses also presented S-T communication channels. From the fifty-seven teacher's comments, thirty-eight reflected feedback and nineteen were used to give instructions. As for the thirtyeight statuses, eighteen introduced assignments, seventeen communicated course information, and three expressed teacher's feedback for the whole class.

Only a limited number of participants $(\mathrm{N}=8)$ recorded particular interactions with the teacher. The examples of S-T communication mentioned in the diaries included receiving teacher's feedback via comments and messages, submitting assignments via messages, and discussing study materials via comments.

One participant perceived S-T communication via Facebook and e-mail equally, as both of them are realized via the Internet. On the other hand, the majority of students $(\mathrm{N}=23)$ noticed improvements in $\mathrm{S}$ T communication. Facebook made communication faster than e-mails, also due to ease of access, lesser formality, or prompt feedback from the teacher. Furthermore, it was perceived as more personal than email communication and fostered S-T interaction outside the language classroom.

However, it is questionable whether there would have been such positive reactions as mentioned above if the teacher had waited for an extended period of time (e.g. a day or two) before responding. This aspect thus needs to be acknowledged as a limitation of the study.

Only nine examples of S-S communication occurred in the available objective data. The visible interaction between students was carried out through comments, a status, and a posted file. Students reacted to others' posts, further explained teacher's instructions, provided course information, and posted a file to help others to prepare for a test.

Twenty-five participants referred to S-S communication in their subjective data. The subjects of their interactions included homework, course information, and study materials. More than one third of the research sample $(\mathrm{N}=13)$ perceived the Facebook group as an improvement in S-S communication. Communication was faster and easier (as it was not necessary to seek for classmates using the Facebook 
search bar). Peer communication outside the classroom and about coursework were also viewed positively.

\section{Implications for language pedagogy practice}

- A Facebook group (and Facebook in general) presents an effective communication platform (also outside the English classroom) - If language learners want to discuss coursework, unfamiliar concepts in notes, or study problems, they can easily message peers or their English teacher (though S-T communication seems less likely to happen).

- Students can send completed homework and extra tasks via messages - This way of submitting assignments can suppress taking too much inspiration from others' work. They can also join peer discussions (about coursework, notes, and study problems) or react to others' posts in the group via comments.

- The English teacher can give instructions and course information or provide feedback through statuses, comments, or messages - Write statuses and comments if you desire to reach the whole audience or write messages if you intend to reach a particular individual!

- The English teacher should manage students' expectations in terms of the turnaround time for feedback - Among other benefits of Facebook, students highly value teacher' immediate and extensively available feedback. They can receive teacher's reaction in a shorter time and do not have to wait for the next contact lesson to learn about the weak/strong spots of their foreign language output. However, the participants should agree on mutually acceptable response routines, so that students can benefit and the teacher is not limited.

- The English teacher should create a set of communication rules a priori - We identified both informal and deviant language in the Facebook group communication. To avoid undesired language, we recommend setting communication boundaries. Consider especially simplified language forms, informal contractions and acronyms, and emojis.

\section{Acknowledgements}

This article is a part of the following projects: UGA V/3/2019 - Lingvodidaktické aspekty využitia Facebooku ako náhrady LMS na hodinách anglického jazyka; APVV-15-0368 - Prax v centre odborovej didaktiky, odborová didaktika v Centre praktickej prípravy.

\section{References}

Al-Shehri, S. (2011). Connectivism: A new pathway for theorising and promoting mobile language learning. International Journal of Innovation and Leadership on the Teaching of Humanities, 1 (2), 10-31.

Anwaruddin, S. M. (2012). Learning English in the Age of Facebook. Journal of Technology for ELT, 2 (3). https://sites.google.com/site/journaloftechnologyforelt/archive/july-2012/5-learning-english-in-the-age-offacebook

Averianova, I. (2012). Social Media in Teaching English: Promises and Problems. Lecture Notes in Information Technology, 14.

Beatty, K. (2010). Teaching and Researching Computer-Assisted Language Learning. London: Pearson Education Limited, 304 p. ISBN 978-1-4082-0500-6.

Brady, K. P., Holcomb, L. B. \& Smith, B. V. (2010). The use of alternative social networking sites in higher educational settings: A case study of the e-learning benefits of Ning in education. Journal of Interactive Online Learning, 9 (2), 151-170.

Datko, J. (2018a). Fostering Self-directed EFL Learning via Facebook Group. MMK, 9, 963-968.

Datko, J. (2018b). The Impact of a Facebook Group on Developing University Students' EFL Competence: A Case Study. QUAERE, 8, 1010-1018.

Hsu, L. (2013). Leveraging Interactivities on Social Networking Sites for EFL Learning. International Journal of English Language Education, 1 (3), 244-270. 
Irwin, C., Ball, L. \& Desbrow, B. (2012). Students' perceptions of using Facebook as an interactive learning resource at university. Australasian Journal of Educational Technology, 28 (7), 1221-1232.

Jong, B., Lai, C.-H., Hsia, Y.-T., Lin, T.-W. \& Liao, Y.-S. (2014). An exploration of the potential educational value of Facebook. Computers in Human Behavior, 32, 201-211.

Kabilan, M. K., Ahmad, N. \& Abidin, M. J. Z. (2010). Facebook: An online environment for learning of English in institutions of higher education? The Internet and Higher Education, 13 (4), 179-187.

Kao, P. \& Craigie, P. (2014). Effects of English Usage on Facebook and Personality Traits on Achievement of Students Learning English as a Foreign Language. Social Behavior and Personality, 42 (1), 17-24.

King, S., Greidanus, E., Carbonaro, M., Drummond, J. \& Patterson, S. (2009). Merging social networking environments and formal learning environments to support and facilitate interprofessional instruction. Medical Education Online, 14 (1). doi: 10.3885/meo.2009.T0000132.

Laire, D., Casteleyn, J. \& Mottart, A. (2012). Social Media's Learning Outcomes within Writing Instruction in the EFL Classroom: Exploring, Implementing and Analyzing Storify. Procedia-Social and Behavioral Sciences, 69, 442-448.

Mazer, J. P., Murphy, R. E. \& Simonds, C. J. (2007). "I'Il see you on Facebook": The effects of computer teacher selfdisclosure on student motivation, affective learning, and classroom climate. Communication Education, 56 (1), 117.

McLoughlin, C. \& Lee, M. J. W. (2010). Personalised and self-regulated learning in the web 2.0 era: International exemplars of innovative pedagogy using social software. Australasian Journal of Educational Technology, 26 (1), 28-43.

Ophus, J. D. \& Abbitt, J. T. (2009). Exploring the potential perceptions of social networking systems in university courses. MERLOT Journal of Online Learning and Teaching, 5 (4), 639-648.

Pascopella, A. \& Richardson, W. (2009). The New Writing Pedagogy. District Administration, 45 (10), 44-46.

Razak, N. A., Saeed, M. \& Zulkifli, A. (2013). Adopting social networking sites (SNSs) as interactive communities among English foreign language (EFL) learners in writing: Opportunities and challenges. English Language Teaching, 6 (11), 187-198.

Roblyer, M. D., McDanielb, M., Webbc, M., Hermand, J. \& Witty, J. V. (2010). Findings on Facebook in higher education: A comparison of college faculty and student uses and perceptions of social networking sites. The Internet and Higher Education, 13 (3), 134-140.

Selwyn, N. (2010). Looking beyond learning: Notes towards the critical study of educational technology. Journal of Computer Assisted Learning, 26 (1), 65-73.

Simpson, M. N. (2012). ESL@Facebook: A Teacher's Diary on Using Facebook. Teaching English with Technology, 12 (3), 36-48.

Small, M. (2014). Theoretical Implementations of Various Mobile Applications Used in English Language Learning. Teaching English with Technology, 4 (1), 35-46.

Stewart, P. (2009). Facebook and Virtual Literature Circle Partnership in Building a Community of Readers. Knowledge Quest, 37 (4), 28-33.

Sun, Y-C. (2010). Extensive writing in foreign-language classrooms: A blogging approach. Innovation in Education and Teaching International, 47 (3), 327-339.

Türkmen, H. G. (2012). Using Social Networking in EFL Classroom in Higher Education. E-learning and Software for Education, 1, 350-354.

Yunus, M. M., Salehi, H. \& Chenzi, C. (2012). Integrating social networking tools into ESL writing classroom: Strengths and weaknesses. English Language Teaching, 5 (8), 42-48. 